\title{
ANALISIS RISIKO KECELAKAAN KERJA DENGAN METODE FAILURE MODE AND EFFECT ANAL YSIS (FMEA) DAN FAULT TREE ANALYSIS (FTA) UNTUK MENURUNKAN TINGKAT RISIKO KECELAKAAN KERJA (PT. BERKAH MIRZA INSANI)
}

\begin{abstract}
Sofian Bastuti
Prodi Teknik Industri Fakultas Teknik Universitas Pamulang, Tangerang Selatan Banten 15417, Indonesia, dosen00954@unpam.ac.id
\end{abstract}

\begin{abstract}
ABSTRAK
PT. Berkah Mirza Insani yang bergerak dibidang pengolahan gas alam menjadi Compressed Natural Gas (CNG) dalam setiap pekerjaan nya selalu mengutamakan Keselamatan dan Kesehatan Kerja (K3) . Penelitian ini mengaplikasikan metode Failure Mode and Effect Analysis (FMEA) didapat RPN tertinggi atau di divisi produksi yang mencakup 8 pekerjaan adalah pada Proses dan langkah pensupplyan CNG ke costumer (operasional PRS) dengan nilai severity 5, occurence 3, detection 4 dan RPN 60. Sedangkan Fault Tree Analysis (FTA) didapat faktor penyebab tingkat risiko tertinggi yaitu Proses dan langkah pensupplyan CNG ke costumer (operasional PRS) saat unloading dan operasional CNG dengan potensi bahaya ledakan Pressure Regulator System (PRS).
\end{abstract}

Kata Kunci: Risiko Kecelakaan Kerja, Metode FMEA, Metode FTA

\section{PENDAHULUAN}

PT. Berkah Mirza Insani yang bergerak dibidang pengolahan gas alam menjadi Compressed Natural Gas (CNG) dalam setiap aktifitas atau pekerjaan nya. Menurut Departemen Keselamatan dan Kesehatan Kerja (DOSH, 2008), untuk melakukan tugas harus dilakukan menjadi rincian ke langkah-langkah spesifik. Setelah itu, setiap langkah untuk bahaya tertentu perlu dianalisis. Selanjutnya, kerja yang aman prosedur untuk menghilangkan atau mengurangi bahaya tersebut dikembangkan dan prosedur kerja yang aman diintegrasikan ke dalam keselamatan dan program kesehatan.

Adapun perumusan masalah dalam penelitian ini yaitu sebagai berikut:

1. Bagaimana hasil aplikasi dari Metode Failure Mode And Effect Analysis (FMEA) untuk mengetahui apa saja potensi risiko yang terjadi pada bagian produksi di PT. Berkah Mirza Insani?
2. Bagaimana hasil implementasi Metode Fault Tree Analysis (FTA) untuk menurunkan potensi risiko kecelakaan kerja pada bagian produksi di PT. Berkah Mirza Insani?

\section{LANDASAN TEORI}

\section{A.Keselamatan dan Kesehatan Kerja (K3)}

Keselamatan adalah Perlindungan orang dari fisik cedera, kesejahteraan mental individu di tempat kerja.

Kesehatan adalah Perlindungan tubuh dan pikiran orang dari penyakit yang dihasilkan dari bahan, proses atau prosedur yang digunakan dalam tempat kerja.

\section{B.Kecelakaan Kerja}

Kecelakaan kerja adalah kejadian yang tidak diinginkan yang berhubungan dengan pekerjaan yang mengakibatkan cidera atau kematian terhadap orang, kerusakan harta benda atau terhentinya proses produksi (Freddin Warsto dan loui Asthur Mamesah, 2003).

Kecelakaan dipicu oleh kegiatan di tempat kerja. Kondisi seperti itu mungkin 
disebabkan oleh aktivitas kerja tertentu dari individu, atau dengan kegiatan orang lain di tempat kerja.

\section{C.Bahaya (Hazard)}

Bahaya adalah sesuatu yang berpotensi menyebabkan kerusakan (ini dapat mencakup artikel, zat, pabrik atau mesin, metode kerja, lingkungan kerja dan aspek pekerjaan lainnya organisasi)

Bahaya yang masuk dalam kategori moderate risk, high risk dan extreme risk akan ditindak lanjuti dengan risk control. Pengendalian risiko dilakukan untuk mengurangi atau menghilangkan risiko.

\section{D.Bahaya Keselamatan Kerja}

Terjadinya kecelakaan kerja sehingga menyebabkan luka, cacat sampai hingga kematian serta kerusakan pada properti. Ini merupakan dampak yang ditibulkan dari Bahaya keselamatan kerja. Klasifikasi bahay yang ada ditempat kerja:
a. Bahaya Mekanik
b. Bahaya Elektrik
c. Bahaya Kebakaran dan Peledakan

\section{E.Risiko (Risk)}

Risiko selalu dihubungkan dengan terjadinya sesuatu yang tidak diinginkan dan merugikan. Dengan demikian risiko merupakan peluang terjadinya sesuatu yang akan mempunyai dampak terhadap sasaran.

Risiko dapat dikategorikan menjadi 5 (lima) kategori (Kolluru, 1996), yaitu:
a. Risiko Keselamatan
b. Risiko Kesehatan
c. Risiko Lingkungan
d. Risiko Publik
e. Risiko Keuangan

\section{F.Manajemen Risiko (Risk Management)}

Manajemen risiko keselamatan dan kesehatan di tempat kerja mempunyai tujuan utama meminimalisir kerugian akibat kecelakaan dan sakit, meningkatkan peluang untuk meningkatkan produksi melalui suasana kerja yang aman, sehat, dan nyaman, memotong mata rantai kejadian kerugian akibat kecelakaan dan penyakit akibat kerja.
Tanggung jawab Manajemen Peraturan Kesehatan dan Keselamatan di Tempat Kerja.

1. melakukan penilaian risiko

2. bekerja sama dengan orang lain yang bekerja di Internet tempat dan, jika perlu, dalam penunjukan koordinator kesehatan dan keselamatan;

3. memberikan informasi yang dapat dipahami kepada orang lain karyawan yang bekerja di tempat mereka.

4. Evaluasi resiko

5. Pengendalian resiko

\section{G.Analisis Risiko (Risk Analysis)}

Analisis risiko merupakan suatu proses evaluasi risiko yang ditimbulkan dari bahayabahaya yang ada dan memberi pengendalian yang memadai atau sesuai atas pengendalian yang telah ada. Dalam proses melakukan analisis risiko perlu memasukan berbagai masukan informasi dan data sebagai bahan pertimbangan untuk menentukan pengendalian yang sesuai dilihat dari tingkat risiko yang telah ada, berikut merupakan pertimbangan-pertimbangan yang harus diperhatikan:

a. Detail lokasi dimana pekerjaan dilakukan.

b. Interaksi bahaya dalam proses aktifitas kerja ditempat kerja.

c. Kemampuan manusia, perilaku, kompetensi, dan ststus kesehatan.

d. Intruksi kerja, sistem kerja, izin kerja, dan kondisi lingkungan.

e. Potensi kegagalan proses dari mesin-mesin.

f. Ketersediaannya kontrol yang ada.

g. Mengamati data yang berhubungan dengan berbagai kecelakaan sehubungan dengan aktifitas kecelakaan pada jenis pekerjaan khusus.

\section{METODOLOGI DAN TEKNIK PENGUKURAN}

\section{A. Failure Mode And Effect Analysis (FMEA)}

FMEA pertama kali digunakan oleh kontraktor untuk NASA pada awal 1960-an. Pada 1967, sipil industri penerbangan mulai menggunakan FMEA dan teknik terkait. 
(FMEA) adalah mencegah terjadinya kecelakaan yang dapat membahayakan nyawa orang. Sasaran ini juga masih berlaku hingga saat ini. hanya sasaran penggunaan Failure Mode And Effect Analys (FMEA) saat ini sudah sangat luas. Namun pada intinya adalah mencegah terjadinya kegagalan dan dampaknya sebelum terjadi.

\section{B.Metode Fault Three Analysis (FTA)}

Fault Tree Analysis merupakan sebuah analytical tool yang menerjemahkan secara grafik kombinasi-kombinasi dari kesalahan yang menyebabkan kegagalan dari sistem. Teknik ini berguna mendeskripsikan dan menilai kejadian di dalam sistem (Foster, 2004). Titik awal analisis FTA adalah pengidentifikasian mode kegagalan pada top level suatu sistem. Sebuah fault tree mengilustrasikan keadaan komponenkomponen sistem (basic event) dan hubungan antara basic event dan top event.

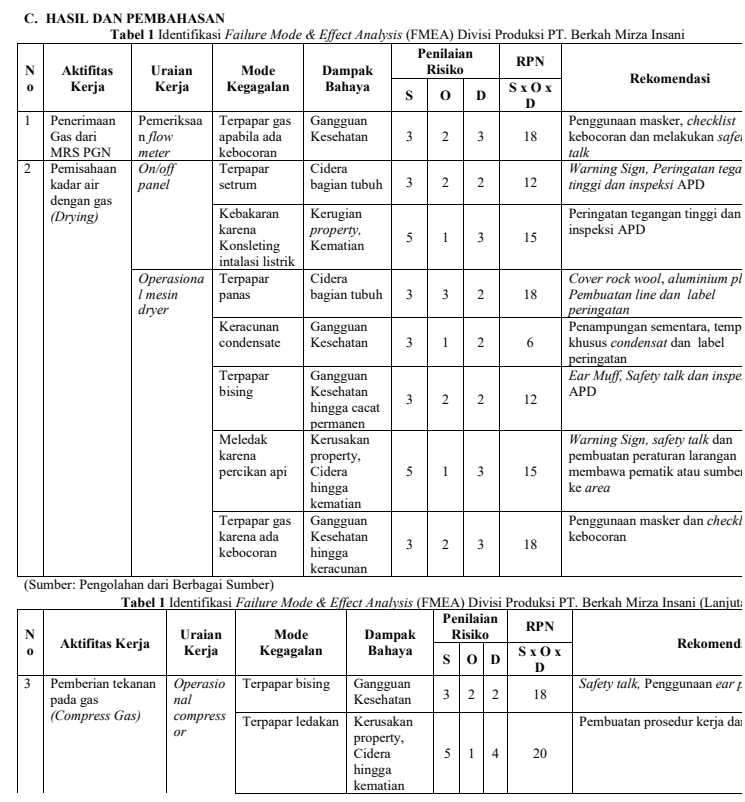

Hasil Hazard Identifikasi Risk Assessment Determining Control keselamatan dan kesehatan kerja dilakukan berdasarkan pengamatan secara langsung dan wawancara kepada pihak yang bertanggung jawab dengan pekerjaan tersebut dan operator yang bekerja langsung di divisi produksi.

a. Penerimaan Gas

b. Drying c. Compress gas

d. Storage

e. Priorarity Panel

f. Filling

g. Delivery

h. Operasional pressure regulator System

\section{HASIL DAN PEMBAHASAN}

Berdasarkan hasil analisa pada tabel FMEA didapat Risk Priority Number tertinggi adalah ledakan Pressure Regulator System (PRS) akan di jadikan Top Event untuk fault Tree.

ledakan pressure regulator system (PRS), bisa disebabkan karena beberapa hal. faktor manusia, faktor mesin dan faktor material merupakan kejadian yang memungkinkan terjadinya ledakan Pressure Regulator System (PRS), maka gerbang pertama yang dipakai mengarah langsung ke top event adalah gerbang OR. Disini kejadian faktor manusia, faktor mesin dan faktor material masih bisa diselidiki lagi penyebabnya, sehingga kejadian tersebut bukan basic event.

Dengan demikian didapat kejadian yang mengarah pada Top event yaitu faktor manusia, faktor mesin dan faktor material dengan Gerbang OR seperti pada Gambar 1.

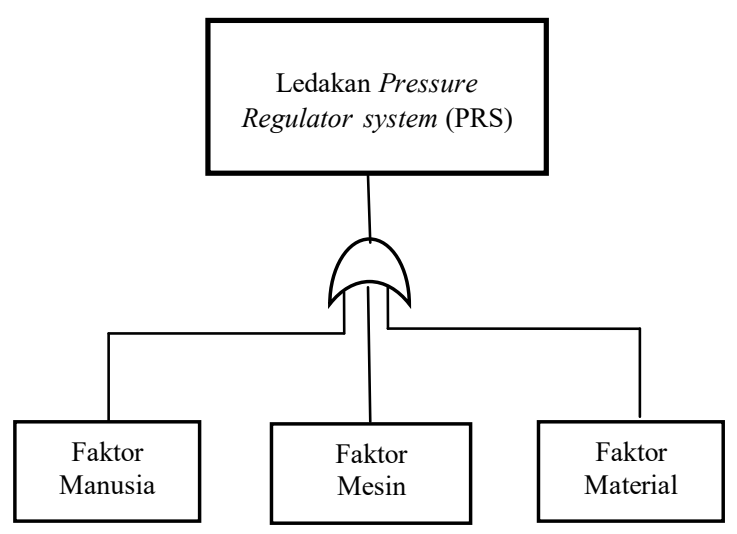

(Sumber: Pengolahan Sendiri)

Gambar 1 Fault Tree-1

Diantara faktor tersebut, jika salah satu terjadi maka terjadi ledakan Pressure Regulator System (PRS) dari Faktor manusia bisa terjadi. Sehingga gerbang kedua yang dipakai adalah Gerbang OR. Hasil pada tahap ini ditunjukan pada Gambar 2. 
(Sumber: Pengolahan Sendiri)

Gambar 2 Fault Tree-2

\section{Mengidentifikasi Minimal Cut Set}

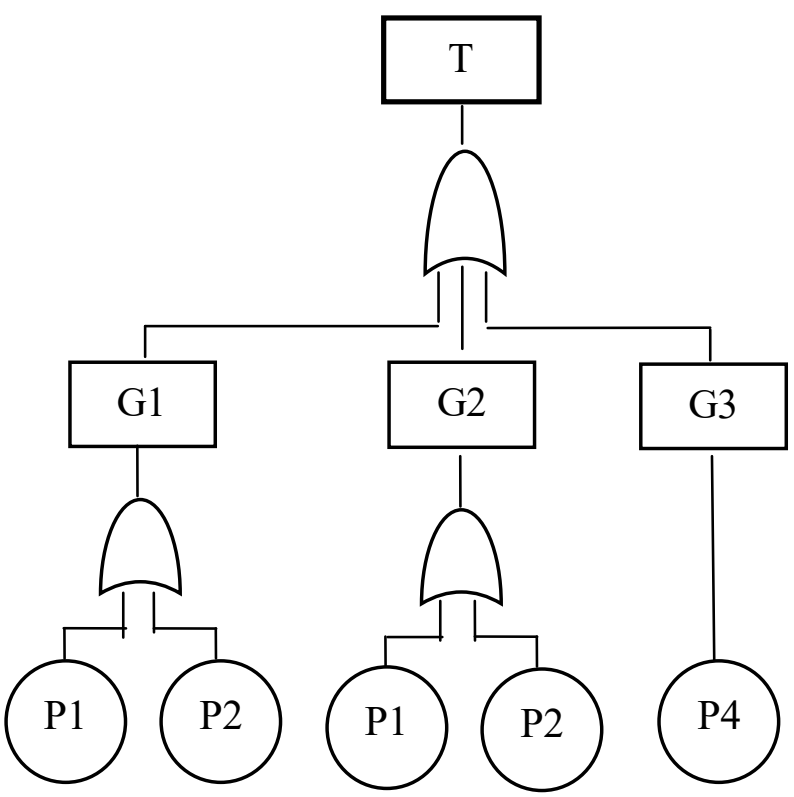

(Sumber: Pengolahan Sendiri)

Gambar 3 Fault Tree dengan Pemisahan

Dari Gambar 3 didapat persamaan

Booleannya:

$\mathrm{T}=\mathrm{G} 1+\mathrm{G} 2+\mathrm{G} 3$

$\mathrm{G} 1=\mathrm{P} 1+\mathrm{P} 2$

$\mathrm{G} 2=\mathrm{P} 3+\mathrm{P} 4$

$\mathrm{G} 3=\mathrm{P} 5$

Menggunakan pendekatan dari atas ke bawah, didapat:

$$
\begin{aligned}
\mathrm{T} & =\mathrm{G} 1+\mathrm{G} 2+\mathrm{G} 3(\text { karena } \mathrm{G} 1=\mathrm{P} 1+\mathrm{P} 2) \\
& =\mathrm{P} 1+\mathrm{P} 2+\mathrm{G} 2+\mathrm{G} 3(\text { karena } \mathrm{G} 2=\mathrm{P} 3+\mathrm{P} 4) \\
& =\mathrm{P} 1+\mathrm{P} 2+\mathrm{P} 3+\mathrm{P} 4+\mathrm{G} 3(\text { karena } \mathrm{G} 3=\mathrm{P} 5) \\
& =\mathrm{P} 1+\mathrm{P} 2+\mathrm{P} 3+\mathrm{P} 4+\mathrm{P} 5
\end{aligned}
$$

Maka Minimal cut set adalah

$\{\mathrm{P} 1\},\{\mathrm{P} 2\},\{\mathrm{P} 3\},\{\mathrm{P} 4\},\{\mathrm{P} 5\}$.

Hasil analisa kualitatif dari terhambatnya proses produksi dengan top event yaitu Ledakan Pressure Regulator System (PRS). Top event terjadi jika kejadian di bawah ini, yaitu kejadian:
a. Operator Baru
b. Kurang Kontrol
c. Tidak Ada Penjadwalan Servis
d. Revisi Check List $\mathrm{CNG}$
e. Over Pressure

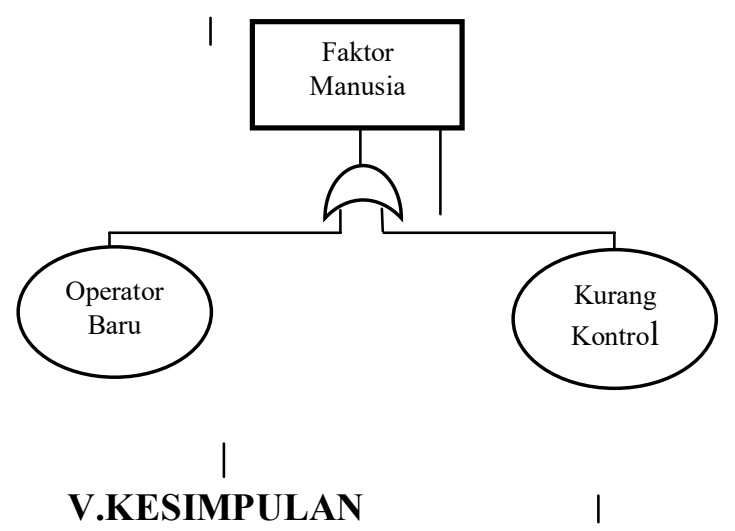

Kesimpulan dari hasil peneltian adalah sebagai berikut:

1. Setelah mengaplikasikan mфtode Failure Mode and Effect Analysis (FMEA) seperti mengetahui pekerjaan, uraian pekerjaan, mode kegagalan, menghitung Risk Priority Number (Severity x Occurence x Detection) didapat RPN tertinggi atau Tingkat risiko tertinggi kecelakaan kerja di divisi produksi yang mencakup 8 pekerjaan adalah pada Proses dan langkah pensupplyan CNG ke costumer (operasional PRS) saat unloading dan operasional CNG dengan potensi bahaya/mode kegagalan ledakan pressure regulator system (PRS) dengan nilai severity 5, occurence 3, detection 4 dan RPN 60.

2. Setelah mengimplementasikan Fault Tree Analysis (FTA) seperti mendefinisikan critical event, pengkontruksian fault tree dan mengidentifkasi minimal cut set didapat faktor penyebab tingkat risiko tertinggi yaitu Proses dan langkah pensupplyan CNG ke costumer (operasional PRS) saat unloading dan operasional CNG dengan potensi bahaya ledakan Pressure Regulator System (PRS) adalah operator baru, kurang kontrol, tidak ada penjadwalan servis, revisi Check List CNG, over Pressure.

\section{DAFTAR PUSTAKA}

Abdul Rahman, B. (2007, January 9). Menangani risiko bahan kimia. Berita Harian, 
Australian Standard/New Zaeland, 2004, Handbook Risk Managemenet Guidlines companion to AS/NZS 4360: 2004, Sydney and Wellington, Author.

Bennet N B Silalahi dan Rumondang B Silalahi. (1995). Manajemen Kesehatan \& Keselamatan Kerja. Jakarta: PT Sapdodadi.

Dewi Diniaty, 2013, Usulan Perbaikan Keselamatan Kerja untuk Meminimumkan Kecelakaan Kerja dengan Metode Job Safety Analysis (JSA) pada Area Lantai Produksi di PT. Alam Permata Riau, Jurnal Sains, Teknologi Dan Industri, Universitas Islam Negeri Sultan Syarif Kasim, Riau.

Dian Palupi Restuputri, 2013, Analisis Kecelakaan Kerja Dengan Menggunakan Metode Hazard And Operability Study, Universitas Muhammadiyah Surakarta, Surakarta.

Gunawan, A. A., 2015, Perbaikan Keselamatan dan Kesehatan Kerja dengan Metode HIRARC di PT. Sumber Rubberindo Jaya, Jurnal Titra, 3(2), 421-426.

Harya Pradhitya, 2012, Identifikasi Penyebab Kecelakaan Kerja dengan Metode Job Safety Analysis (JSA) dan Failure Mode and Effect Analysis (FMEA) pada Divisi Assembly di PT.Tjahja Sakti Motor, Universitas Bina Nusantara, Jakarta.

Pillay, A., and Wang, J. "Modified failure mode and effects analysis using approximate reasoning," Reliability Engineering and System Safety Vol. 79, No. 1, 2003, pp. 69-85.

Ramli, S., 2010, Pedoman Praktis Manajemen Risiko Dalam Perspektif K3 OHS Risk Management, PT. Dian Rakyat, Jakarta.

Ramli, S., 2010, Sistem Manajemen Keselamatan dan Kesehatan Kerja OHSAS 18001, PT. Dian Rakyat, Jakarta.
Somad. I, “ Teknik Efektif Dalam Membudayakan Keselamatan \& Kesehatan Kerja "Halaman 93-94. Dian Rakyat, Jakarta. 2013

Tamrin, S.B.M., and Aumran, N., (2014). Acomparison of the hazards, the risks, and the types of control in three selected agricultural industries.

Yusuf Wachyudi. (2010). Identifikasi Bahaya, Analisis, dan Pengendalian Risiko Dalam Tahap Desain Proses Produksi Minyak \& Gas Di Kapal Floating Production Storage \& Offloading (Fpso) Untuk Projek Petronas Bukit Tua Tahun 2010. Tesis. Jakarta: Universitas Indonesia. 